\title{
Erratum to: Evaluation of IGF1R and phosphorylated IGF1R as targets in HER2-positive breast cancer cell lines and tumours
}

\author{
Brigid C. Browne $\cdot$ Alex J. Eustace $\cdot$ Susan Kennedy $\cdot$ Neil A. O'Brien • \\ Kasper Pedersen - Martina S. J. McDermott • Annemarie Larkin • \\ Jo Ballot · Thamir Mahgoub - Francesco Sclafani - Stephen Madden · \\ John Kennedy · Michael J. Duffy · John Crown · Norma O'Donovan
}

Published online: 4 November 2014

(C) Springer Science+Business Media New York 2014

\section{Erratum to: Breast Cancer Res Treat (2012) \\ 136:717-727 \\ DOI 10.1007/s10549-012-2260-9}

In the original publication, the authors stated that "high levels of IGF1R and PIGF1R were associated with higher $\mathrm{IC}_{50}$ values for NVP-AEW541, with $\mathrm{p}$ values approaching statistical significance (IGF1R: $P=0.053$; pIGF1R: $P=0.078$ )". This statement should read as "high levels of IGF1R and pIGF1R were associated with lower $\mathrm{IC}_{50}$ values for NVP-AEW541". Consequently high IGF1R and pIGF1R levels are weakly predictive of sensitivity to NVP-AEW541. These updated data have no significant effect on any of the other statistical correlations listed in the article.
The online version of the original article can be found under doi:10.1007/s10549-012-2260-9.

B. C. Browne $(\bowtie) \cdot$ A. J. Eustace · K. Pedersen .

M. S. J. McDermott - A. Larkin · S. Madden - J. Crown ·

N. O'Donovan

Molecular Therapeutics for Cancer Ireland, National Institute for

Cellular Biotechnology, Dublin City University, Glasnevin,

Dublin 9, Ireland

e-mail: brigid.browne2@mail.dcu.ie

S. Kennedy · M. J. Duffy

Department of Pathology and Laboratory Medicine,

St Vincent's University Hospital, Dublin 4, Ireland

N. A. O'Brien

Division of Hematology and Oncology, University of California,

Los Angeles, USA

\author{
J. Ballot $\cdot$ T. Mahgoub $\cdot$ F. Sclafani $\cdot$ J. Crown \\ Department of Medical Oncology, St Vincent's University \\ Hospital, Dublin 4, Ireland \\ J. Kennedy \\ Department of Medical Oncology, St James's Hospital, \\ Dublin 8, Ireland \\ M. J. Duffy \\ UCD School of Medicine and Medical Science, Conway \\ Institute, University College Dublin, Dublin 4, Ireland
}

